\title{
Verificação da temática biodiesel no Enem (1998-2017) em consonância com sua evolução no contexto nacional
}

\author{
Thalyta Pessoa Freire, Geórgia Batista Vieira de Lima \& Luciano Leal de Morais \\ Sales
}

Universidade Federal de Campina Grande, Centro de Formação de Professores, Unidade Acadêmica de Ciências Exatas e da Natureza, Rua Sérgio Moreira de Figueiredo, Casas Populares, Cajazeiras 58900-000, Paraíba, Brasil. E-mail: thalytafreire1@gmail.com, georgiabvl_@hotmail.com

Freire T.P., Lima G.B.V. \& Sales L.L.M. (2018) Verificação da temática biodiesel no Enem (1998-2017) em consonância com sua evolução no contexto nacional. Pesquisa e Ensino em Ciências Exatas e da Natureza, 2(2): 242-257. http://dx.doi.org/10.29215/pecen.v2i2.1073

Editor acadêmico: Silvânio Silvério Lopes da Costa. Recebido: 01 Março 2018. Aceito: 15 Junho 2018. Publicado: 28 Dezembro 2018.

Resumo: O Exame Nacional do Ensino Médio (Enem) foi criado em 1998 e desde lá passou por duas mudanças. Exige dos candidatos a articulação dos conhecimentos aprendidos no ensino médio, relacionando-os com ilustrações, para encontrar uma resolução aos problemas. Entre eles, a produção e uso de biodiesel é um dos assuntos cobrados na matriz do exame. Portanto, a pesquisa procurou entender o perfil das questões sobre este biocombustível, considerando a sua abordagem, o contexto nacional e a apresentação das informações sobre ele na avaliação. De um universo de 1.503 questões (1998 e 2017) foram selecionadas nove. Entre as edições de 1998 e 2002 não houve a menção direta ao biocombustível escolhido. De 2003 em diante, o exame aborda desde a transformação do óleo vegetal em biodiesel, através da reação de transesterificação, às suas políticas de uso e produção.

Palavras chave: Biocombustível, ensino contextualizado, química, ensino médio.

\section{Verification of the biodiesel theme in Enem (1998-2017) in connection with its evolution in the national} context

Abstract: The Exame Nacional do Ensino Médio (Enem) was created in 1998 and has undergone two changes since then. It demands from the candidates the articulation of the knowledge learned in high school, relating them with illustrations, to find a resolution to the problems. Among them, the production and use of biodiesel is one of the subjects charged in the matrix of the exam. Therefore, the research sought to understand the profile of the questions about this biofuel, considering its approach, the national context and the presentation of the information about it in the evaluation. From a universe of 1.503 questions (1998 and 2017), nine were selected. Between the editions of 1998 and 2002 there was no direct mention of the biofuel chosen. From 2003 onwards, the exam addresses from the transformation of vegetable oil into biodiesel, through the transesterification reaction, to its use and production policies.

Key words: Biofuel, contextualized teaching, chemistry, high school.

\section{Introdução}

Desde sua criação, o Exame Nacional do Ensino Médio (Enem) vem evoluindo seu caráter sociopolítico. Em contraste, com a memorização de conhecimentos ao longo do Ensino Médio, o Enem trabalha a resolução de problemas baseados no exercício da cidadania e no mundo do trabalho, considerando as tecnologias utilizadas pela sociedade nessas atividades (Brasil 1998).

Hoje, sua aplicação acontece em todo o território nacional, anualmente. A participação é voluntária para os candidatos que estão concluindo ou já concluíram o Ensino Médio, incluindo 
aqueles que necessitam de atenção específica, como é o caso de pessoas com deficiências físicas, lactantes, idosos, pessoas privadas de liberdade e jovens sob medidas socioeducativas (Brasil 2017).

Uma característica importante deste exame é que ele tem acompanhado o avanço científico-tecnológico ao longo dos anos em que o Ministério da Educação (MEC), responsável pelo seu planejamento, execução e avaliação, juntamente com o Instituto Nacional de Pesquisas Educacionais Anísio Teixeira (INEP) o tem aplicado (Cruz 2011).

Criado em 1998, o Enem passou por mudanças significativas em 2009, deixando de ser o chamado "Velho Enem" e passando a ser o "Novo Enem". Até 2008, o exame era constituído de uma redação e 63 questões objetivas realizadas em um único dia, a partir de 2009, o exame passou a ter 180 questões objetivas divididas em quatro áreas de conhecimento e aplicado em dois dias seguidos, sendo 45 de cada uma das áreas do exame ("Ciências Humanas e suas Tecnologias" e "Ciências da Natureza e suas Tecnologias" no sábado e "Linguagens, Códigos e suas Tecnologias" e "Matemática e suas Tecnologias" no domingo), além de uma redação também no segundo dia (Andrade 2012; Ferreira 2014).

Em 2017, o Enem passou por outra reformulação. Após uma consulta pública foi decidido que o exame seria realizado em dois domingos seguidos, deixando também de emitir o certificado de conclusão do Ensino Médio. A maioria dos entrevistados optou em manter a prova presencial ao invés de virtual (INEP 2017).

Apesar do Brasil estar entre as dez maiores economias do mundo, no ranking de desenvolvimento tecnológico ocupou a $43^{\text {a }}$ posição em 2016, patamar de países em desenvolvimento, como Bolívia, Peru e Trinidad e Tobago. Isso pode ser atribuído à falta de investimentos no setor de ciência e tecnologia (C\&T). Especialistas justificam, inclusive, a importância desses investimentos na busca de alternativas para a miséria e desigualdade social (Vasconcelos 2016).

A exemplo desta associação entre o desenvolvimento tecnológico e fatores socioeconômicos, pode ser citado o Programa Nacional de Produção e Uso do Biodiesel (PNPB), criado em 2004, que busca alternativas sustentáveis para utilização de óleo diesel, desenvolvendo a agricultura familiar e investindo em pesquisas científicas a fim de melhorar a produção e uso desse biocombustível (ANP 2016).

Após a implementação do PNPB, o Enem tem utilizado o biodiesel como temática para algumas questões. São explorados o seu conceito, suas aplicações, vantagens, rendimento energético em massa, resistência oxidativa, adulteração de combustíveis em relação ao percentual obrigatório e tecnologias necessárias para a sua produção e utilização em território nacional (Mattei 2010).

Com base neste contexto, o presente estudo buscou responder quais os conhecimentos necessários para a resolução de questões do Enem referentes ao biocombustível, com o objetivo de compreender a maneira como o exame aborda os conteúdos da sua Matriz de Referência, levantando um breve histórico do avanço da produção e utilização do biodiesel no Brasil. Assim, investigou de que forma o Enem inclui dados atuais e como exige do aluno a percepção da sua convivência com os temas abordados.

\section{Metodologia}

A pesquisa surgiu a partir da observação da inserção de temas ambientais nos objetos de conhecimento associados à matriz de referência do Enem, publicada em 2009, pelo MEC. Escolheu-se o biodiesel e sua abordagem após um aprofundamento neste tema e a sua recorrência nas provas do Exame Nacional do Ensino Médio.

O cotidiano é à base das questões da Matriz de Referência de Ciências da Natureza e suas Tecnologias do Enem. Segundo Maceno et al. (2011), o Enem emerge como uma possibilidade de introdução das mudanças curriculares e pedagógicas que valorizam a conexão entre a ciência, a tecnologia e as questões sociais, priorizando a integração das disciplinas e a mobilização das 
informações diante de situações do cotidiano, desconsiderando o ensino propedêutico e indo além da memorização superficial dos conteúdos.

Sob a percepção de que o exame traz cenários que ajudam ao candidato a refletir sobre as práticas sociais através dos instrumentos tecnológicos, o biodiesel é um importante tema a ser levado em consideração, pois desponta como um substituinte ao óleo diesel mineral, uma vez que é biodegradável, não tóxico e produzido a partir de fontes renováveis (Knothe et al. 2006).

O desenvolvimento da pesquisa se deu a partir do levantamento de questões das provas do Exame Nacional do Ensino Médio desde a sua criação em 1998 até o ano de 2017 e que constam no site oficial do INEP com abordagem à temática "Biodiesel", de forma direta ou indireta. Ao todo, foram observadas onze avaliações do Velho Enem (1998-2008), com um total de 693 questões, das quais foram extraídas três, e 17 avaliações do Novo Enem (2009-2017), com 810 questões de "Ciências Exatas e da Natureza", onde seis foram selecionadas.

Ou seja, de um universo de 1503 itens, foram selecionados 9. A Tabela 1 abaixo exibe informações dos itens analisados, com suas respectivas identificações: ano, tipo de abordagem, número da questão, aplicação e cor da prova selecionada. É importante lembrar que, embora escolhida a cor identificada nesta tabela, às demais cores apresentam as mesmas questões, mas com a ordem alterada.

Tabela 1. Informações a respeito das questões selecionadas.

\begin{tabular}{|c|c|c|c|c|}
\hline Ano & Abordagem & Questão & Aplicação & Caderno \\
\hline 2003 & Rendimento do óleo de girassol comparado ao óleo diesel. & 40 & Primeira & Amarelo \\
\hline 2004 & $\begin{array}{l}\text { Experimentação do biodiesel como substituinte aos } \\
\text { combustíveis fósseis. }\end{array}$ & 43 & Primeira & Amarelo \\
\hline 2008 & $\begin{array}{l}\text { Benefícios da introdução dos biocombustíveis na matriz } \\
\text { energética brasileira. }\end{array}$ & 28 & Primeira & Amarelo \\
\hline 2011 & Rendimento energético em massa de alguns biocombustíveis. & 49 & Segunda & Branco \\
\hline 2011 & Reação de transesterificação. & 57 & Segunda & Branco \\
\hline 2012 & Reação de transesterificação. & 75 & Segunda & Branco \\
\hline 2014 & Resistência oxidativa. & 54 & Primeira & Azul \\
\hline 2016 & Adulteração de combustíveis. & 76 & Terceira & Branco (9) \\
\hline 2017 & Funções orgânicas. & 96 & Primeira & Amarela \\
\hline
\end{tabular}

Em seguida, após a coleta e seleção das questões, foi realizada uma investigação com o objetivo de compreender quais eram os conhecimentos necessários para que os candidatos pudessem responder corretamente às questões. Concomitante a esta análise, buscou-se entender qual o contexto do biodiesel no Brasil no momento da aplicação do item, a fim de compreender como o Enem explorou o tema diante daquela realidade. Os resultados aqui apresentados concentram-se principalmente numa abordagem química.

\section{Resultados e Discussão}

No que se diz respeito à Química, a matriz de referência do exame traz os biocombustíveis juntamente com combustíveis fósseis e energia nuclear listados no tópico "Energias Químicas no Cotidiano". Os conteúdos são definidos com a perspectiva de incluir o aluno de forma consciente no que tange a busca por alternativas sustentáveis diante dos problemas ambientais (Marcelino \& Recena 2012).

Entre 1998 e 2003, o termo biodiesel não foi inserido em nenhuma das questões do exame. As primeiras avaliações de viabilidade do uso de óleos vegetais in natura e de biodiesel começaram em 1982, quando foram realizados testes com a colaboração da indústria automobilística, mas o governo federal só lançou programas para seu desenvolvimento em 2002 e o inseriu na matriz energética brasileira em 2005 (Suarez \& Meneghetti 2007).

Em 2003, a questão 40 (Figura 1) do caderno amarelo contextualiza a respeito do uso do óleo de girassol como combustível alternativo ao óleo diesel. Outras informações significativas também são constatadas no enunciado deste item, quanto ao óleo de girassol ser menos 
poluente, proveniente de fonte renovável, ainda estar em fase experimental e possuir maior rendimento em relação ao óleo diesel.

O setor de transporte, que concentra uma grande parcela da demanda de energia no país, continuamente busca,
alternativas de combustíveis.
Investigando alternativas ao óleo diesel, alguns especialistas apontam para o uso do óleo de girassol, menos
poluente e de fonte renovável, ainda em fase experimental. Foi constatado que um trator pode rodar, nas mesmas
condições, mais tempo com um litro de óleo de girassol, que com um litro de óleo diesel.
Essa constatação significaria, portanto, que usando óleo de girassol,
(A) o consumo por km seria maior do que com óleo diesel.
(B) as velocidades atingidas seriam maiores do que com óleo diesel.
(C) o combustível do tanque acabaria em menos tempo do que com óleo diesel.
(D) a potência desenvolvida, pelo motor, em uma hora, seria menor do que com óleo diesel.
(E) a energia liberada por um litro desse combustível seria maior do que por um de óleo diesel.

Figura 1. Item $\mathrm{n}^{\circ}$ 40, presente no ENEM 2003. Fonte: INEP (2017).

A questão tanto no enunciado quanto nas alternativas explora as vantagens do óleo de girassol como substituinte ao óleo diesel. No Brasil esse assunto ganhou destaque nacional em 2002 com o programa nacional de substituição do diesel de petróleo, que foi batizado de PROBIODIESEL na Portaria MCT n ${ }^{0}$ 702, de 30 de outubro de 2002, e no ano de 2003 com os primeiros estudos para a criação de uma política do biodiesel no país, criando a Comissão Executiva Interministerial do Biodiesel (GEIB) e o Grupo Gestor (GG) pelo governo federal. (Brasil 2002).

Diversas notícias foram publicadas em maio de 2003 sobre a temática da questão 40, sendo isso possibilitado pela realização da Exposição Feira Agropecuária, Industrial e Comercial de Maringá (Expoingá) e do Seminário sobre Fontes Alternativas de Combustível. A notícia selecionada (Figura 2) é do Portal Folha de Londrina, publicada em 14 de maio de 2003, com informações básicas a respeito do baixo custo e fácil manuseio do óleo de girassol, além da programação do evento com seminários e palestras.

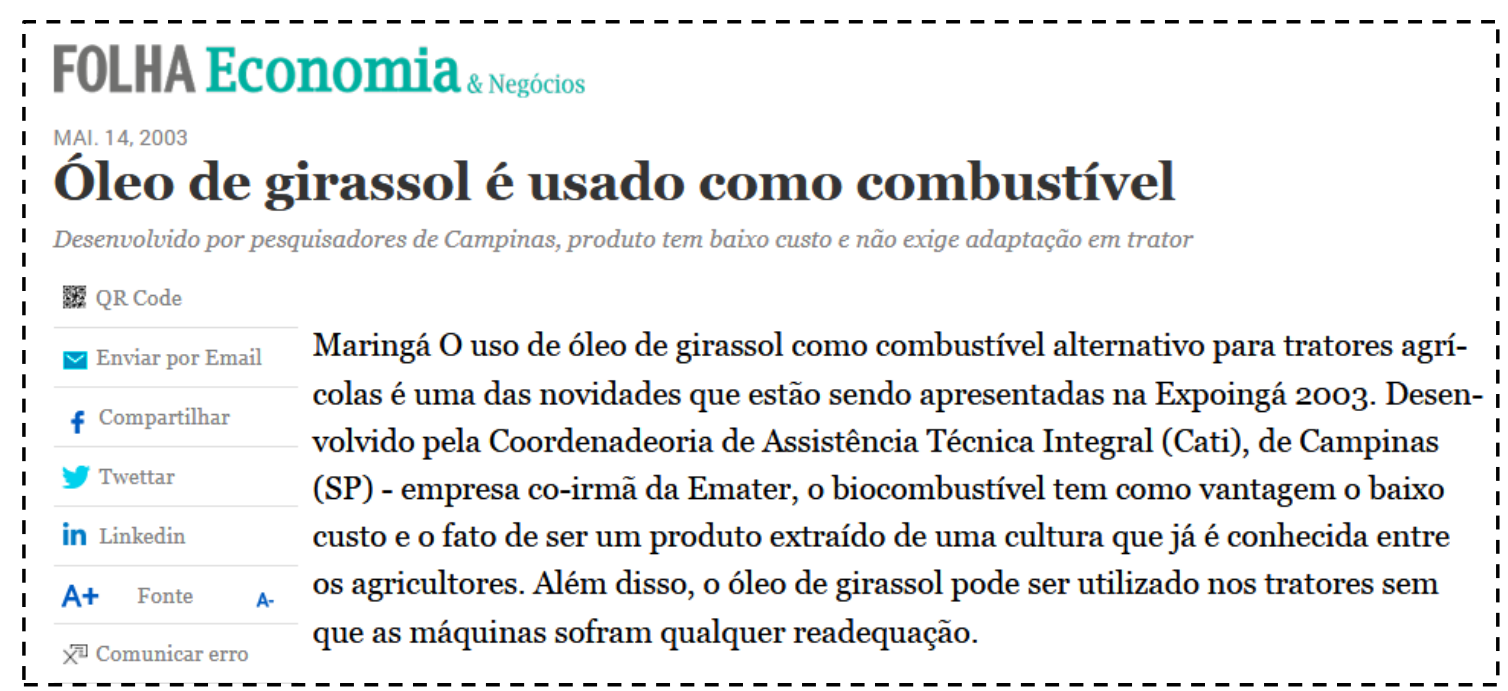

Figura 2. Folha de Londrina noticia o uso de óleo de girassol em fase experimental. Fonte: Parra (2003).

Para responder à questão o estudante não necessitava de conhecimentos específicos sobre composição, produção, utilização, benefícios ou impactos ambientais do óleo de girassol e óleo diesel. No entanto, são necessários conceitos fundamentais de Física sobre potência, velocidade, rendimento e energia, conteúdos presentes nos livros didáticos do $1^{\mathrm{a}}$ ano do Ensino Médio. A resposta correta seria a letra "e". 
O óleo de girassol debatido na questão 40 se trata do óleo bruto, obtido a partir de sementes de girassol, quimicamente inalterado, utilizado na cozinha e que serve também para movimentar motores, inclusive os de irrigação e dos tratores. Entretanto, existe confusão em alguns materiais sobre a nomenclatura, onde biodiesel e óleo vegetal são usados como sinônimos. $\mathrm{O}$ biodiesel é resultante de um processo químico, a reação de transesterificação, onde o principal elemento é a biomassa (Suarez et al. 2007).

A palavra biodiesel apareceu pela primeira vez em uma questão do Velho Enem somente em 2004. As suas informações se mostram bastante contextualizadas. A questão 43 do caderno amarelo do exame de 2004 (Figura 3) aborda a preocupação com o declínio da produção mundial de petróleo e a busca por medidas, principalmente no setor de transportes, por combustíveis renováveis em substituição ao petróleo.

A questão busca uma alternativa de combustível renovável, que seja utilizado nos transportes além do etanol. O Brasil é o pioneiro na implantação de programas de incentivo a biocombustíveis, com destaque para o PROÁLCOOL, lançado em 1975, sendo o crescimento do setor sucroalcooleiro estimulado pelo forte investimento do governo.

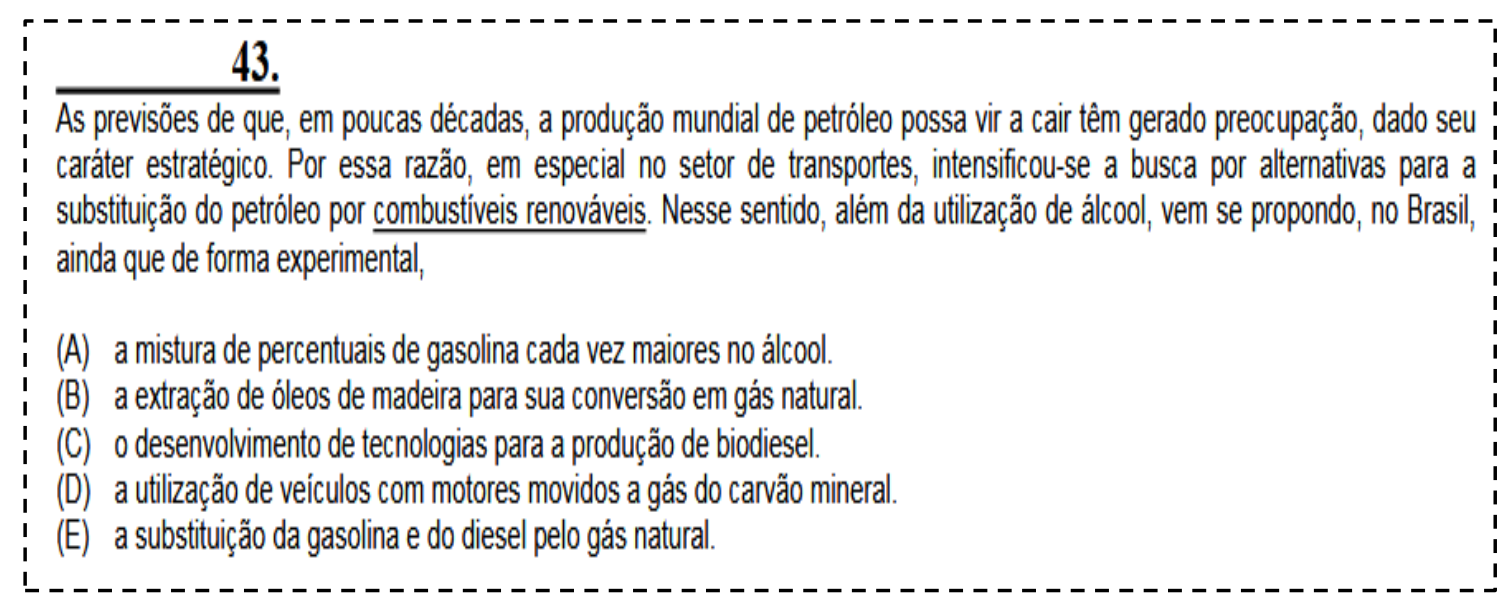

Figura 3. Item $n^{0} 43$, presente na prova amarela do ENEM de 2004. Fonte: INEP (2017).

Em 2003, um fato marcou o surgimento de um novo impulso para o setor, com a fabricação dos veículos flex-fuel, os quais podem usar indiscriminadamente álcool ou gasolina. Com isso a popularização e produção do álcool acentuou o seu crescimento. No ano de 2004, a venda de veículos flex-fuel aumentou em mais de cinco vezes, atingindo 328 mil unidades (Mendonça et al. 2008).

Diferentemente do álcool, o biodiesel ainda estava em fase de desenvolvimento, mas em 2004 foi lançado o Programa Nacional de Produção e Uso do Biodiesel (PNPB), por meio da Medida Provisória $\mathrm{n}^{0} 214$ que posteriormente foi convertida na Lei 11.097/2005, tendo como principal objetivo garantir a produção viável economicamente do combustível renovável, com enfoque na inclusão social e no desenvolvimento regional e também a sua mistura ao diesel fóssil, em caráter experimental (Brasil 2005).

A reportagem publicada no dia 01 de maio de 2004 (Figura 4) no portal Ambiente Brasil aborda o lançamento do PNPB, a realização de testes complementares, inserção da agricultura familiar no processo, previsões animadoras sobre a produção nacional do biocombustível e desenvolvimento regional, além de expressar os avanços do Programa Biodiesel em diversos estados do Nordeste.

Em um aspecto geral, para resolução do item 43, além de conceitos atuais, o aluno necessitava de uma carga de conhecimentos de Química Orgânica básica, apenas sobre os tipos de combustíveis renováveis e não renováveis. $O$ contexto das informações auxiliava fortemente os estudantes na busca pela alternativa correta. Os conteúdos abordados são apresentados nos livros didáticos de Química para o $3^{\circ}$ ano do Ensino Médio. A resposta correta seria a letra "c". 
Em 2008, o tema biodiesel esteve presente na questão 28 (Figura 5) do caderno amarelo. Assim como os demais itens investigados da avaliação, o combustível renovável é abordado como alternativa aos combustíveis derivados do petróleo, alertando para os benefícios ao meio ambiente. $\mathrm{O}$ contexto do enunciado trata da Lei $\mathrm{n}^{\circ} 11.097 / 2005$, que introduziu o biodiesel na matriz energética brasileira, além da definição de biocombustível.

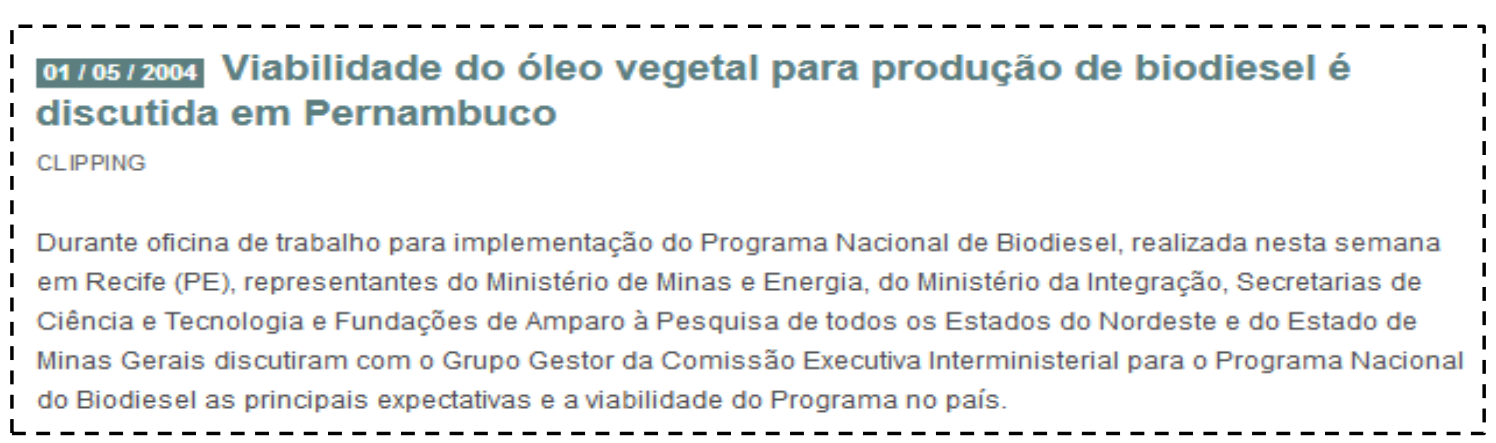

Figura 4. Ambiente Brasil noticia porque é possível utilizar óleo vegetal para a produção de biodiesel. Fonte: Ambiente Brasil (2004).

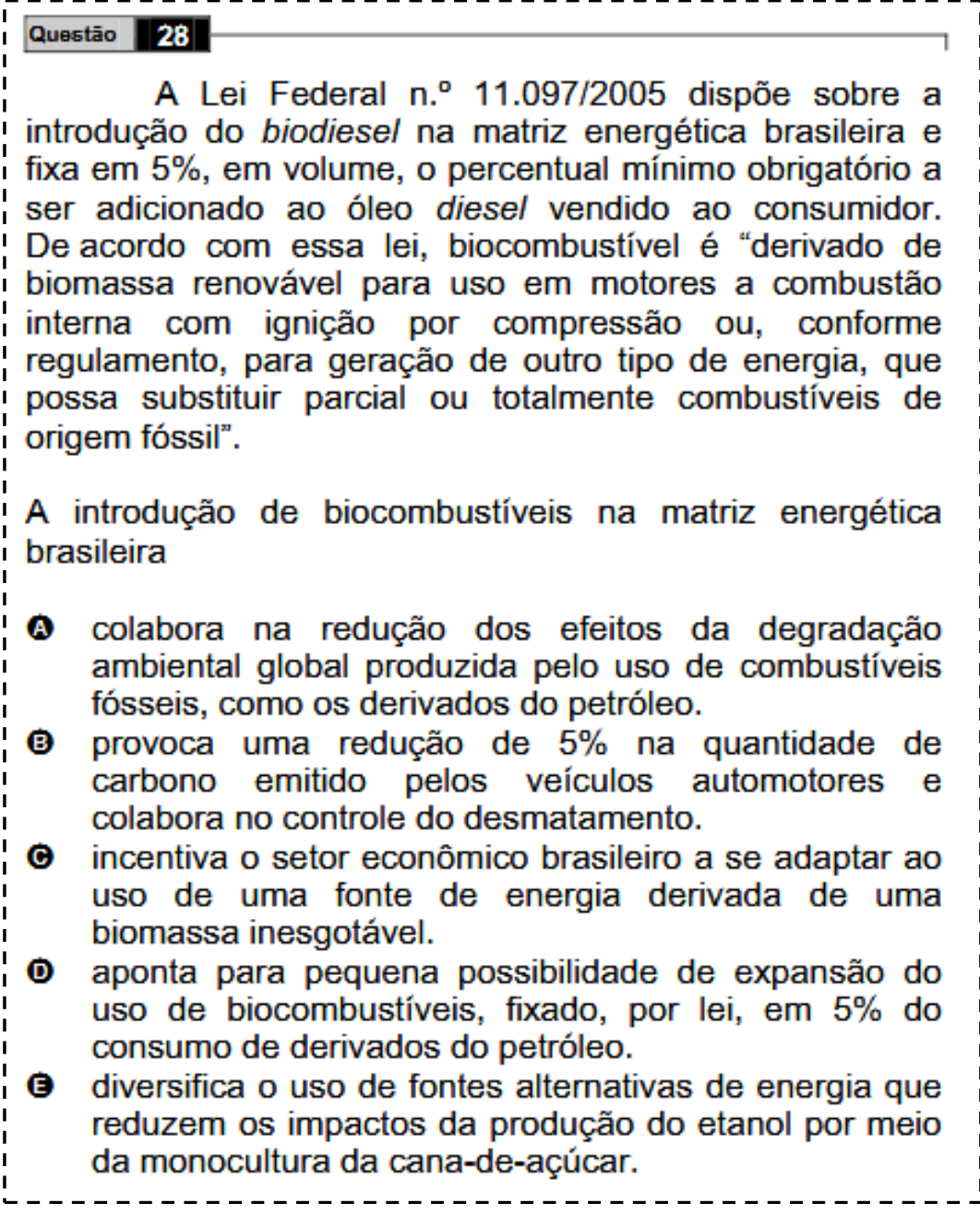

Figura 5. Item $n^{0}$ 28, presente no caderno amarelo do ENEM 2008. Fonte: INEP (2017).

Em 24 de novembro de 2004, foi divulgada a Resolução da Agência Nacional de Petróleo, Gás Natural e Biocombustíveis (ANP) n ${ }^{0} 42$, que determinou o teor de adição nacional do biodiesel ao óleo diesel na proporção de 2\% (B2). Entre 2005 e 2007, a comercialização era voluntária. 
A obrigatoriedade veio no artigo $2^{\circ}$ da Lei $n^{\circ} 11.097 / 2005$, que estabeleceu que todo o diesel de petróleo comercializado no território nacional, deveria conter $2 \%$ de biodiesel. No entanto, o governo federal antecipou para 5\% (B5) a mistura do biodiesel ao diesel comum a partir de 2010 (ANP 2017). fóssil no Brasil.

A Tabela 2 mostra a evolução periódica do percentual de biodiesel presente no diesel

Tabela 2. Teor de biodiesel conforme período. Fonte: Adaptada de ANP (2017).

\begin{tabular}{cc}
\hline Período & Determinação de biodiesel \\
\hline 2003 & Facultativo \\
Janeiro de 2008 & $02 \%$ \\
Julho de 2008 & $03 \%$ \\
Julho de 2009 & $04 \%$ \\
Janeiro de 2010 & $05 \%$ \\
Agosto de 2014 & $06 \%$ \\
Novembro de 2014 & $07 \%$ \\
\hline
\end{tabular}

As informações disponibilizadas na questão são imprescindíveis para a sua resolução. O leitor deveria estar inteirado sobre a Lei 11.097/2005 e conceitos a respeito de fontes renováveis de energia. Não havia menção à evolução percentual de biodiesel presente no diesel fóssil no país, como também que no ano de 2008 a determinação de biodiesel subiu de $2 \%$ para $3 \%$, sendo a obrigatoriedade do $5 \%$ antecipada para começar a vigorar em 2010. A resposta correta seria a letra “a”.

A Lei $n^{0}$ 13.263/2016 alterou a Lei $n^{0} 13.033 / 2014$ determinando um cronograma de aumento do teor de biodiesel a partir de 2017. Atualmente o diesel vendido nos postos pelo Brasil possui $8 \%$ de biodiesel e $92 \%$ de diesel, no entanto esse volume aumentou em março de 2018 passando a ser 10\% de biodiesel (BRASIL 2016).

Existe ainda a possibilidade de usar mais biodiesel. O Conselho Nacional de Política Energética poderá aumentar esse percentual até 15\% a qualquer momento após março de 2019. A Figura 6 mostra quanto de biodiesel o país utilizou ou utilizará em cada ano (ANP 2017).

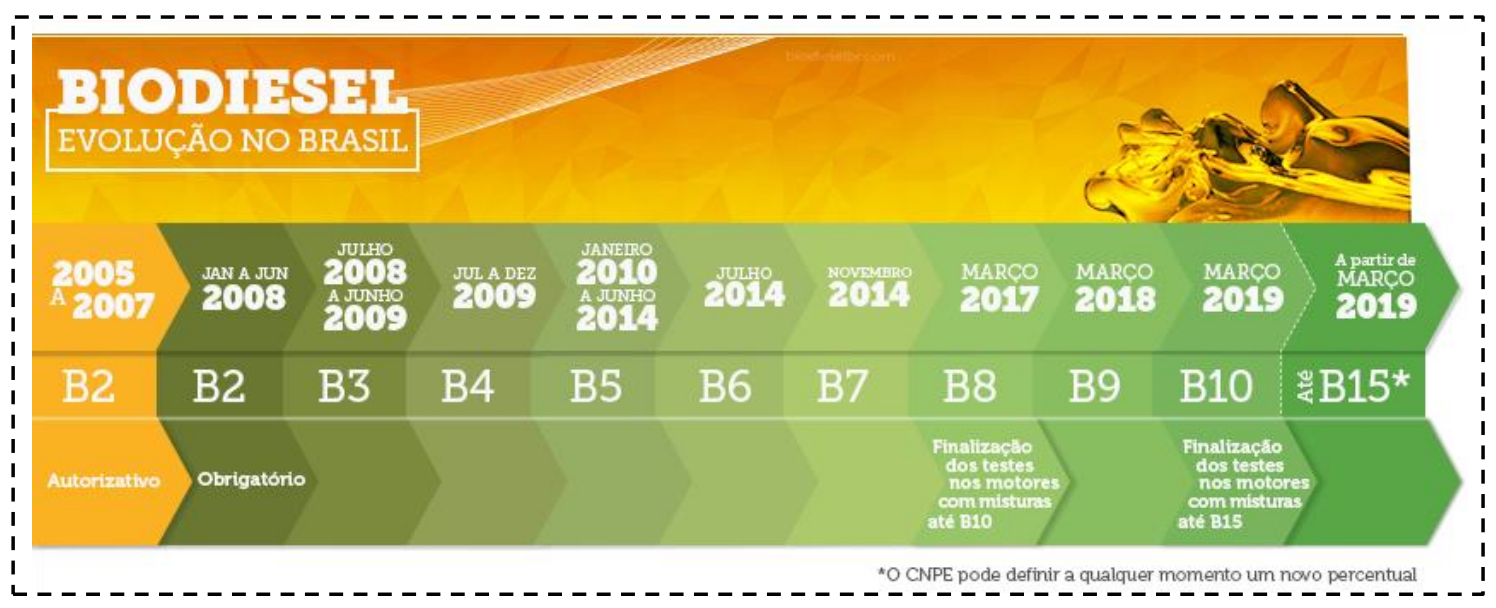

Figura 6. Evolução do biodiesel em território nacional. Fonte: Biodiesel.br (2017).

O Enem para pessoas privadas de liberdade (Enem PPL) em 2011 apresentou o maior número de questões sobre o biocombustível entre todas as 29 avaliações analisadas. A questão 49 (Figura 7) do $1^{\text {o }}$ dia no caderno 3 (branco), da segunda aplicação, demonstrou seguir uma tendência a contextualização e integração de conteúdos diversificados da Química, semelhante às questões do Velho Enem já investigadas.

A questão 49 utiliza conhecimentos da Termoquímica, ramo da química que estuda a energia absorvida ou liberada nas transformações. Este conteúdo é apresentado nos livros 
didáticos do $2^{\mathrm{a}}$ ano do Ensino Médio, sendo a combustão assunto permanente. Toda combustão é uma reação exotérmica, na qual um combustível reage com o $\mathrm{O}_{2}$, que é o comburente, liberando energia. A principal utilidade de qualquer combustível é liberar energia na forma de calor quando participa de uma reação de combustão.

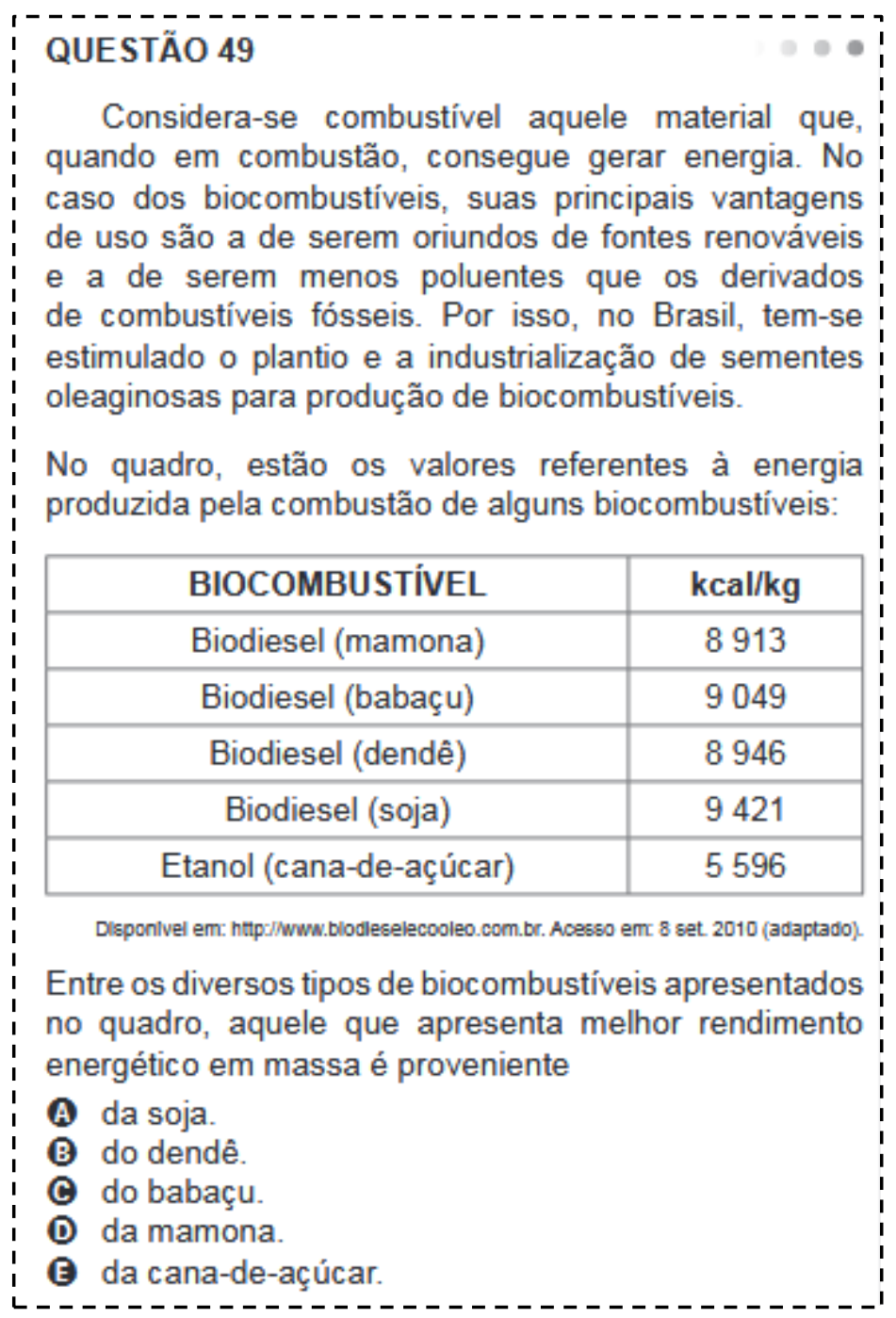

Figura 7. Item no 49, presente no caderno branco do ENEM 2011, segunda aplicação. Fonte: INEP (2017).

O item apresenta no quadro o tipo de biocombustível à esquerda e o poder calorífico por unidade de massa correspondente à direita, em $\mathrm{kcal} / \mathrm{kg}$, onde as massas dos combustíveis são iguais. Uma das formas de comparar o rendimento dos diferentes combustíveis é analisar seus poderes caloríficos, grandeza definida como a quantidade de energia liberada na queima de uma unidade de massa do material combustível. A resposta correta seria a letra "a”.

Dados da ANP (2017) mostram a distribuição dos tipos de matérias-primas utilizadas no Brasil para a produção do biodiesel (B100) entre os anos de 2007 a 2016, conforme a Figura 8.

Como se pode notar no gráfico abaixo, o óleo de soja continuou sendo a principal matéria-prima para a produção de biodiesel (B100). A segunda matéria-prima no "ranking" de produção das usinas é a gordura animal, mesmo depois da diminuição em relação a 2015, seguida pelos outros materiais graxos com maior participação em relação aos demais períodos e óleo de algodão.

A questão 57 (Figura 9) também da mesma prova de 2011 demonstra sua direta relação com o quesito anterior, exibindo um esquema do processo de produção do biodiesel a partir do óleo de soja. $\mathrm{O}$ enunciado é objetivo quanto à necessidade da reação química para transformação de óleo vegetal ou gordura animal em combustível alternativo. Assim como nas demais provas, 
exalta os benéficos dos biocombustíveis serem oriundos de fontes renováveis e produzirem muito menos poluição do que os derivados do petróleo.

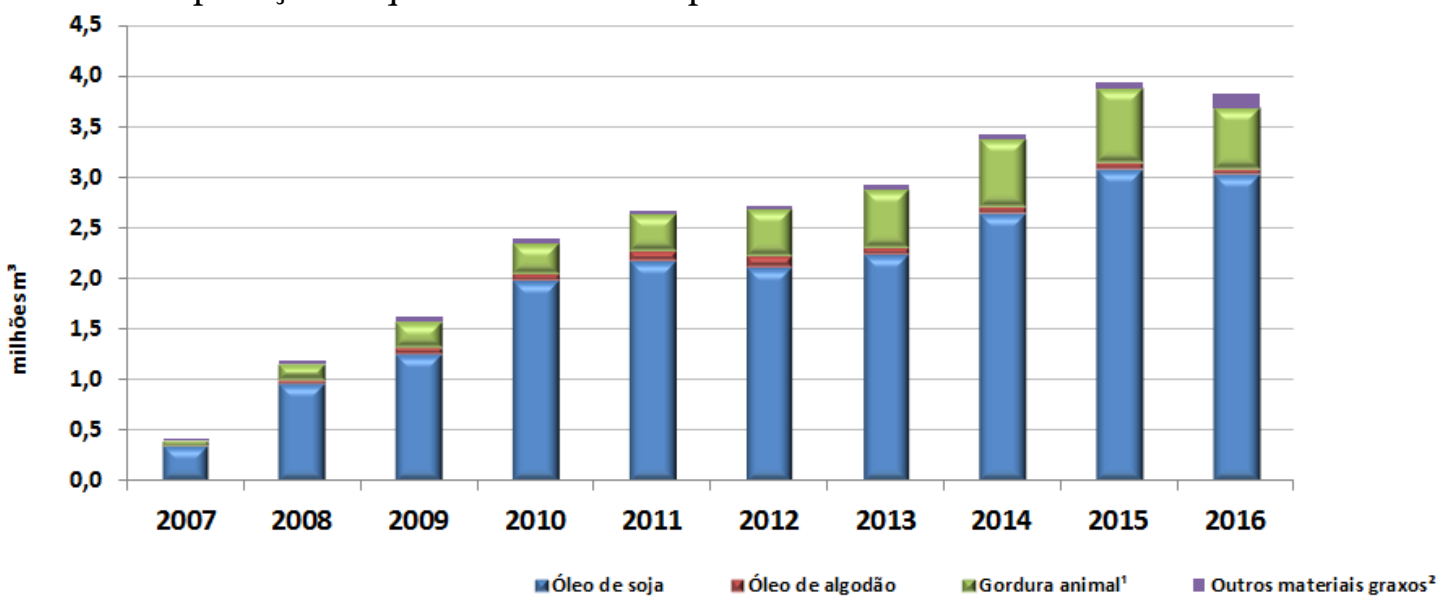

Figura 8. Evolução das matérias-primas na produção de biodiesel no Brasil: ${ }^{1}$ Inclui gordura bovina, de frango e de porco; ${ }^{2}$ Inclui óleo de palma de amendoim, óleo de nabo-forrageiro, óleo de girassol, óleo de mamona, óleo de sésamo, óleo de fritura usado e outros materiais graxos. Fonte: ANP (2017).

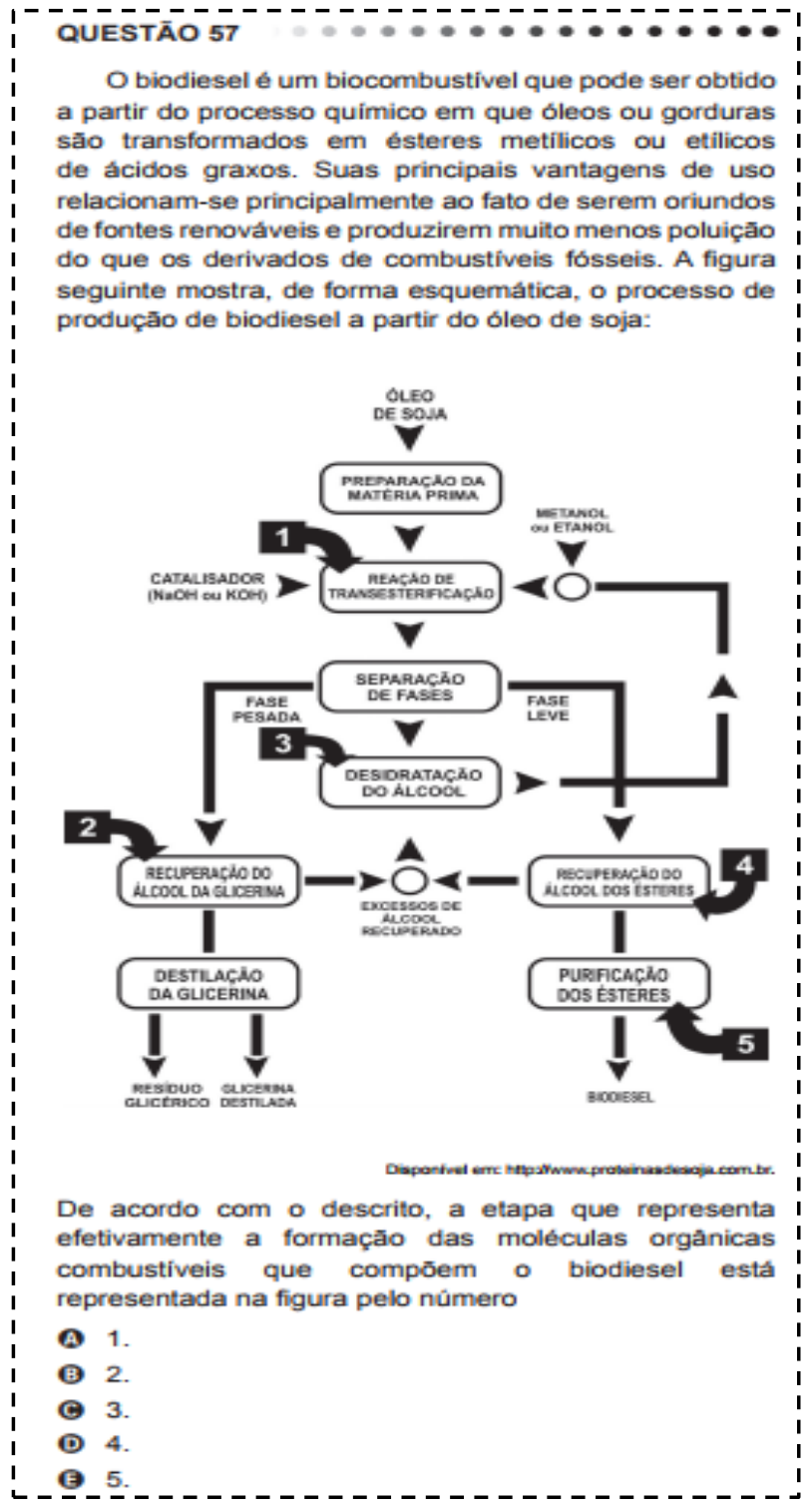

Figura 9. Item no 57, presente no caderno branco do ENEM 2011, segunda aplicação. Fonte: INEP (2017). 
Para a resolução do item seria necessário do leitor a compreensão da reação química denominada transesterificação, em que o triglicerídeo (matéria-prima) que constitui o óleo ou gordura reage com o álcool, formando uma mistura de ésteres alquílicos (o biodiesel) e, como subproduto, outro álcool. Santos \& Pinto (2009) descrevem a reação de transesterificação como sendo uma "reação dos triglicerídeos presentes nos óleos vegetais ou gorduras animais com álcool em presença de catalisador”.

A Figura 10 apresenta a reação de transesterificação de um triglicerídeo.



Figura 10. Transesterificação de um triglicerídeo. Fonte: Garcia (2006).

Do ponto de vista químico, o óleo vegetal usado na produção de biodiesel é um triglicerídeo, ou seja, um triéster derivado da glicerina. Sob ação de um catalisador básico $(\mathrm{NaOH}$ ou $\mathrm{KOH})$ e na presença de metanol ou etanol (podendo utilizar também propanol, butanol e álcool amílico), o óleo sofre uma transesterificação formando três moléculas de ésteres metílicos ou etílicos dos ácidos graxos, que constituem o biodiesel em sua essência, e liberando uma molécula de glicerol ou glicerina.

O subproduto do esquema da questão 57 é a glicerina, de sabor adocicado, que purificada (grau USP ou glicerina farmacêutica) tem grande aplicação nos setores de cosméticos, higiene pessoal, alimentos, medicamentos e fumo (Mota et al. 2009). A alternativa correta seria a letra "a".

Em 2012, assim como 2011, a primeira aplicação do Exame não contou com questões sobre o tema biodiesel, somente a segunda aplicação. A questão 75 (Figura 11) do $1^{\circ}$ dia, caderno 3 , apresentava um dos métodos de obtenção do biodiesel envolvendo o óleo de soja e utilizando como álcool o metanol em meio básico e alertava quanto a necessidade de a reação acontecer na ausência de água.

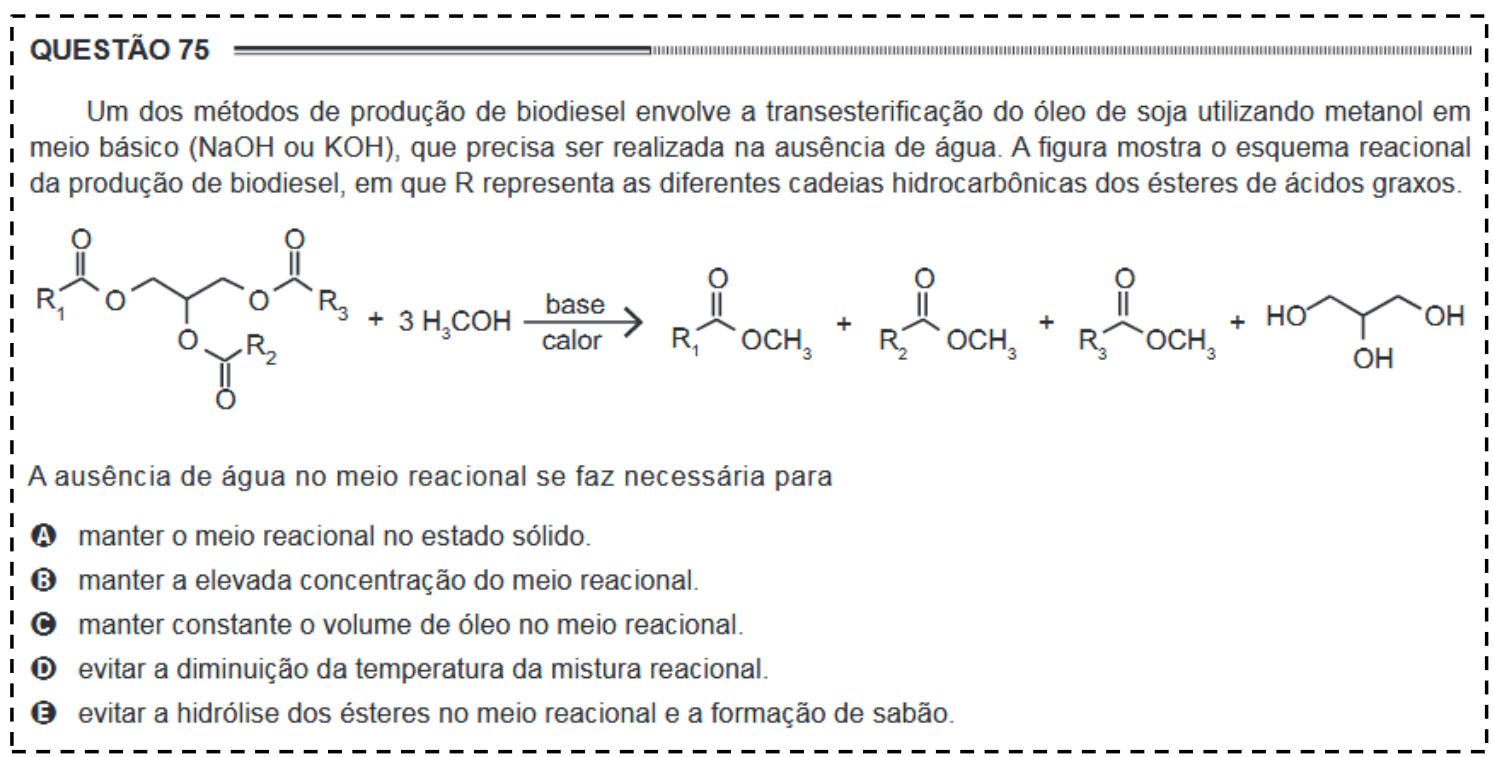

Figura 11. Item $n^{0} 75$, presente no caderno branco do ENEM 2012, segunda aplicação. Fonte: INEP (2017). 
No item 75 analisado é questionado qual a necessidade da ausência de água no meio reacional. Com isso, seria necessário do aluno compreender que, a presença considerável de água no meio reacional, favorece a reação de hidrólise do triglicerídeo (reação de saponificação) em presença de base, forma-se sabão e glicerol. A formação de sabão é indesejável, pois permite maior solubilização do glicerol nos ésteres etílicos, dificultando o processo de separação de fases (Santos \& Pinto 2009). A alternativa correta seria a letra “e”.

O item 54 (Figura 12) do caderno azul de 2014 tratou da instabilidade do biocombustível frente ao oxigênio que reside nas insaturações, ou duplas ligações, entre os carbonos das moléculas. $\mathrm{O}$ enunciado iniciava com a classificação do biodiesel como uma mistura e a variação das suas propriedades quanto à composição. Também apresentava um quadro que ilustrava o teor médio de ácidos graxos de algumas fontes oleaginosas, sendo este fundamental para identificação da fonte que produziria um biodiesel de maior resistência à oxidação.

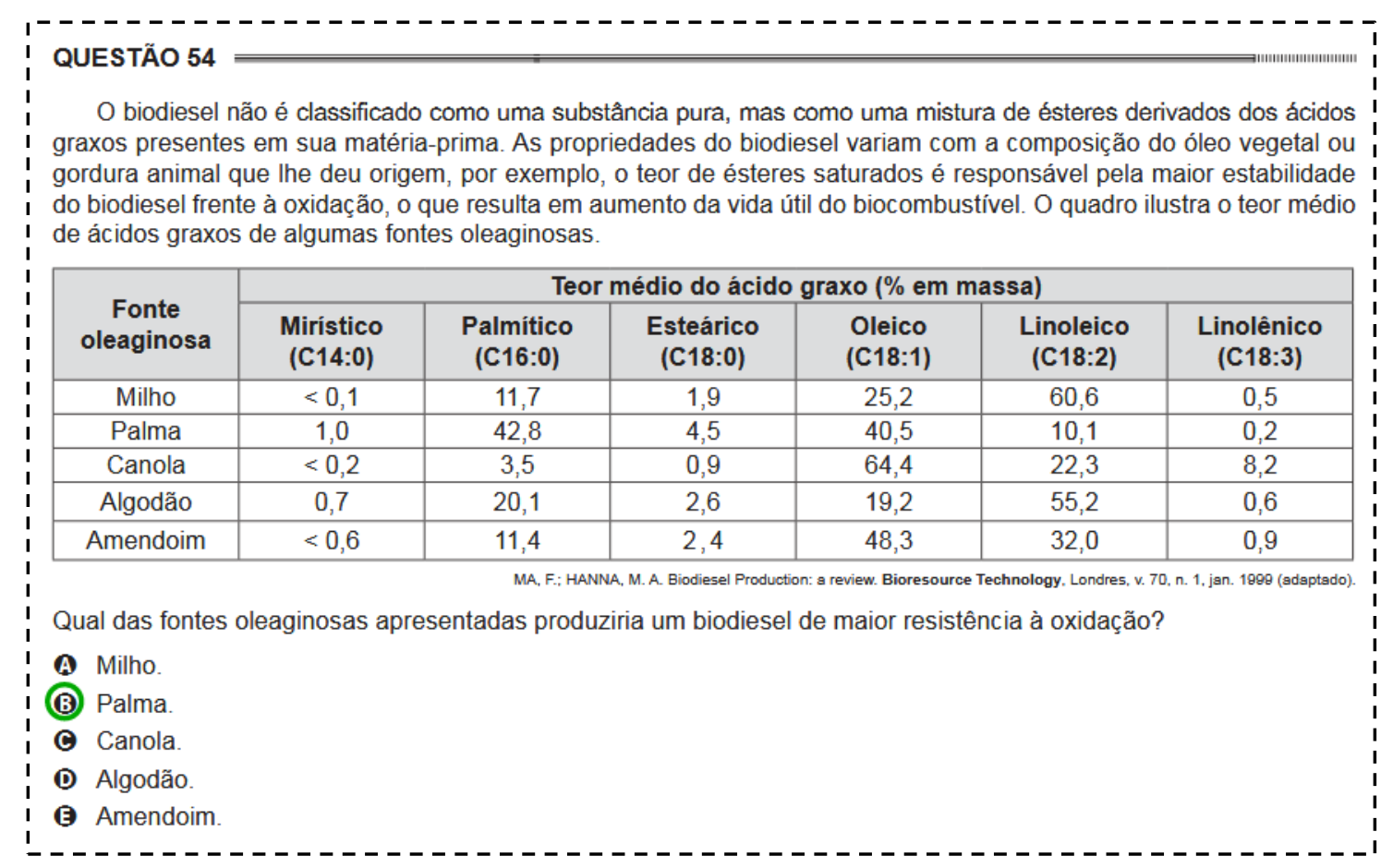

Figura 12. Item $n^{\circ} 54$, presente no caderno azul do ENEM 2014. Fonte: INEP (2017).

A oleaginosa de origem acaba por influenciar na estabilidade do biodiesel. Os ácidos graxos são ácidos carboxílicos de cadeia longa, livres ou esterificados. Quando saturados, possuem pouca reatividade química, já os ácidos graxos insaturados, são mais reativos e mais suscetíveis a termo-oxidação. A alternativa correta seria a letra "e".

A Tabela 3 apresenta a composição de ácidos graxos em alguns óleos vegetais e gorduras. O óleo de soja não é ilustrado no quadro da questão 54. A fonte oleaginosa da soja é a principal matéria-prima para a produção do biodiesel, no entanto, apresenta muitas duplas ligações, o que o torna bastante instável.

A questão 76 (Figura 13) caderno branco (9), do $1^{\circ}$ dia, na terceira aplicação, trata da adulteração de combustíveis automotivos pela adição de substâncias ou matérias de baixo valor comercial, que ao invés de proporcionar os benefícios dos biocombustíveis, pode danificar os motores, aumentar o consumo de combustíveis e prejudicar o meio ambiente. $\mathrm{O}$ texto ainda alerta quanto à mistura do diesel fóssil ao biodiesel legalmente obrigatória em território nacional, não citando a Lei ${ }^{0}$ 13.263/2016 que determinou um cronograma de aumento do teor de biodiesel a partir de 2017.

A ANP mantém o Programa de Monitoramento da Qualidade dos Combustíveis (PMQC), que coleta e analisa amostras de combustíveis em postos de todo o Brasil, visando 
atender ao disposto no artigo $8^{\circ}$ da Lei 9.478/1997, em particular os incisos que tratam da garantia de qualidade e do suprimento de combustíveis ao mercado nacional (Brasil 1997).

O monitoramento da qualidade de combustíveis é importante não somente em função do desempenho dos veículos, mas, devido ao impacto ambiental das emissões de poluentes. A adulteração dos combustíveis se caracteriza pela adição irregular de qualquer substância, sem recolhimento de impostos, com vistas à obtenção de lucro (ANP 2018).

$\mathrm{O}$ item apresenta um quadro com valores de quatro propriedades (densidade, poder calorífico, viscosidade e teor de enxofre) do diesel, biodiesel e do óleo vegetal, solicitando a partir das informações do quadro quais as duas propriedades que podem ser empregadas tecnicamente para verificar se uma amostra de diesel comercial está ou não adulterada com óleo vegetal. Realizando uma análise simples do quadro, é possível observar a alta viscosidade do óleo vegetal $\left(37.0 \mathrm{~mm}^{2} / \mathrm{s}\right)$ em relação ao diesel $\left(3.9 \mathrm{~mm}^{2} / \mathrm{s}<37.0 \mathrm{~mm}^{2} / \mathrm{s}\right)$ e biodiesel $\left(4.7 \mathrm{~mm}^{2} / \mathrm{s}<37.0 \mathrm{~mm}^{2} / \mathrm{s}\right)$.

Tabela 3. Composição de óleos e gorduras de diversas origens. Fonte: Rinaldi et al. (2007).

\begin{tabular}{lccccccc}
\hline Óleo ou Gordura & \multicolumn{7}{c}{ Composição em ácidos graxos (\% em massa) } \\
\hline & Láurico & Mirístico & Palmítico & Esteárico & Oléico & Linoléico & Linolênico \\
& $\mathrm{C}_{12} \mathrm{H}_{24} \mathrm{O}_{2}$ & $\mathrm{C}_{14} \mathrm{H}_{28} \mathrm{O}_{2}$ & $\mathrm{C}_{16} \mathrm{H}_{32} \mathrm{O}_{2}$ & $\mathrm{C}_{18} \mathrm{H}_{34} \mathrm{O}_{2}$ & $\mathrm{C}_{18} \mathrm{H}_{32} \mathrm{O}_{2}$ & $\mathrm{C}_{18} \mathrm{H}_{30} \mathrm{O}_{2}$ & $\mathrm{C}_{18} \mathrm{H}_{28} \mathrm{O}_{2}$ \\
\hline Algodão & - & 1.5 & 22 & 5.0 & 19 & 50 & - \\
Amendoim & - & 0.5 & $6.0-11.4$ & $3.0-6.0$ & $42.3-61$ & $13-33.5$ & - \\
Babaçu & $44-45$ & $15-16.5$ & $5.8-8.5$ & $2.5-5.5$ & $12-16$ & $1.4-2.8$ & - \\
Coco & 44 & $13-18.5$ & $7.5-11$ & $1.0-3.0$ & $5.0-8.2$ & $1.0-2.6$ & - \\
Dendê & -51 & $0.6-2.4$ & $32-45$ & $4.0-6.3$ & $38-53$ & $6.0-12$ \\
Girassol & - & - & $3.6-6.5$ & $1.3-3.0$ & $14-43$ & $44-68$ & - \\
Linhaça & - & - & 6.0 & 4.0 & $13-37$ & $5.0-23$ & $26-58$ \\
Milho & - & - & 7.0 & 3.0 & 43 & 39 & - \\
Oliva & - & 1.3 & $7.0-16$ & $1.4-3.3$ & $64-84$ & $4.0-15$ & - \\
Soja & - & - & $2.3-11$ & $2.4-6.0$ & $23.5-31$ & $49-51.5$ & $2.0-10.5$ \\
Sebo & - & $3.0-6.0$ & $25-37$ & $14-29$ & $26-50$ & $1.0-2.5$ \\
\hline
\end{tabular}

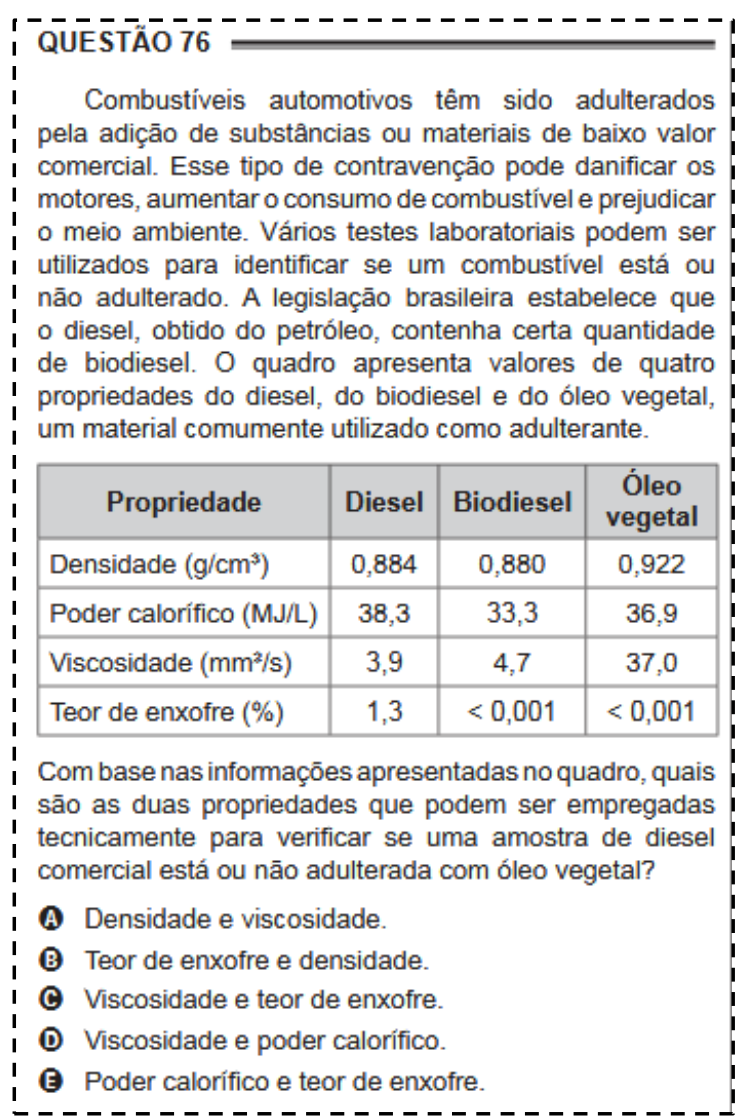

Figura 13. Item $n^{0} 76$, presente no caderno branco (9) do ENEM 2016, terceira aplicação. Fonte: INEP (2017). 
O óleo vegetal possui o valor da densidade maior que o diesel, em misturas entre os dois combustíveis, quanto maior for a porcentagem de óleo vegetal, maior será a densidade da mistura. A densidade e a viscosidade são estáveis durante o período de armazenamento, por isso, estas propriedades podem ser empregadas tecnicamente para verificar se o diesel comercial está ou não adulterado com óleo vegetal. A alternativa correta é a letra "a".

No enunciado da questão 96 (Figura 14) do caderno amarelo do segundo dia do exame (2017), a informação de que a reação de transesterificação representa a etapa efetiva da formação das moléculas orgânicas combustíveis que compõem o biodiesel é omitida, exigindo a identificação da função orgânica do produto.

O biodiesel é uma mistura de ésteres metílicos de ácidos graxos, obtido a partir da reação de triglicerídeos que reage com um álcool na presença de uma base ou ácido forte, produzindo uma mistura de ésteres de ácidos graxos e glicerol, conforme a equação química ilustrada na questão (Geris et al. 2007). A função química presente no biodiesel é o éster, constituindo o grupo funcional R'-COOR". A alternativa correta é a letra "b".

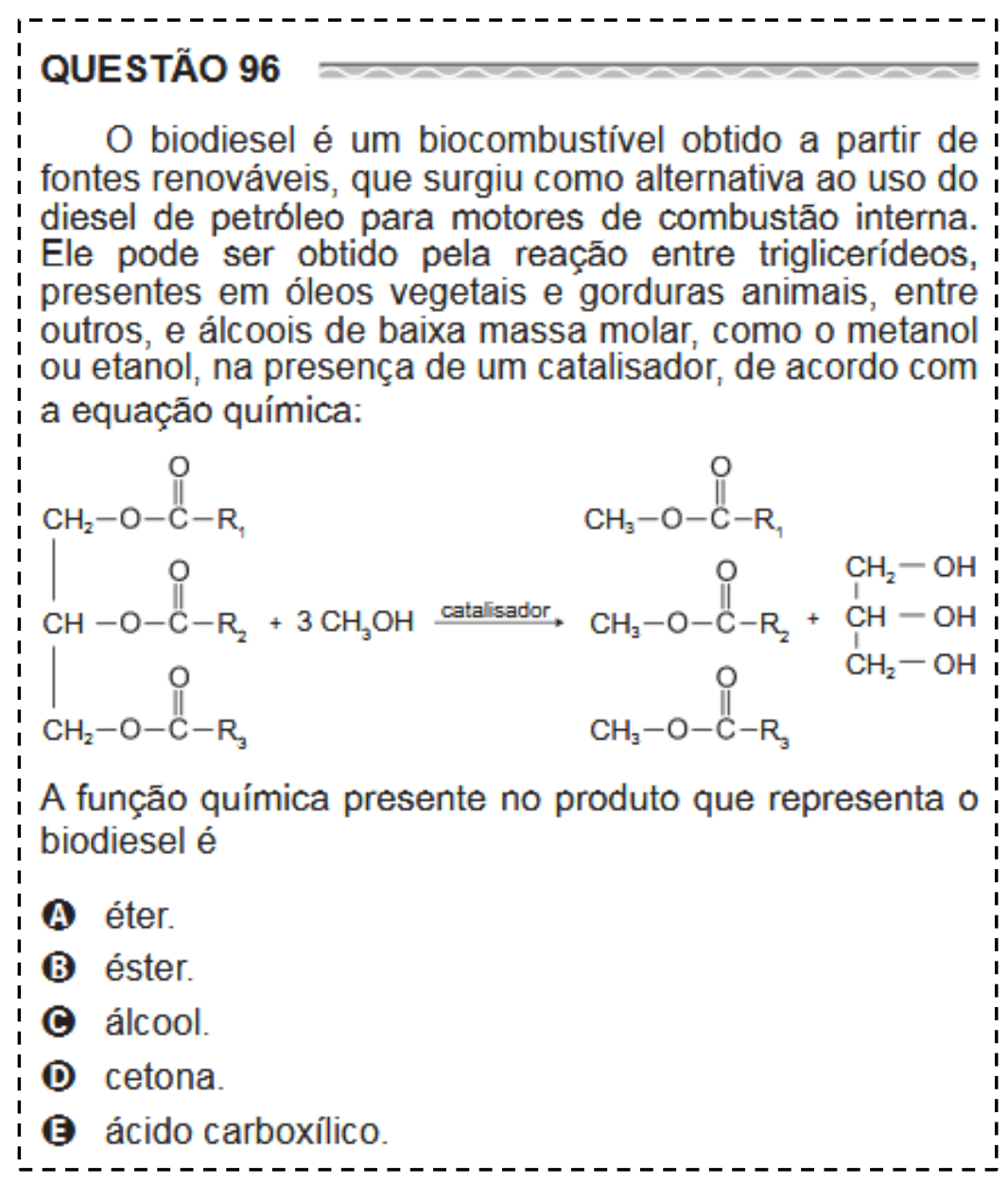

Figura 14. Item $n^{\circ} 96$, presente no caderno amarelo do ENEM 2017. Fonte: INEP (2017).

A exploração dos aspectos do cotidiano é uma característica forte nas questões de diferentes edições do Enem. Desde sua criação, o exame é realizado a partir de uma matriz de competências e habilidades que seguem tendências internacionais de avaliação, onde as mudanças sociais se processam e alteram a vida cotidiana, exigindo padrões elevados da escolaridade e indicam a formação de alunos que "possam assimilar informações e utilizá-las em contextos adequados, interpretando códigos e linguagens e servindo-se dos conhecimentos adquiridos para a tomada de decisões autônomas e socialmente relevantes” (INEP 1998: 8).

Os enunciados das questões envolvem temas bastante contextualizados abordando aspectos da possível substituição parcial ou total dos combustíveis fósseis por bicombustíveis 
para solução de problemas ambientais, exigindo do candidato a interpretação de forma a mobilizar suas habilidades e conhecimentos desenvolvidos durante sua trajetória escolar. A maioria dos itens está relacionada, principalmente, aos benefícios ambientais do biodiesel e reação de transesterificação.

É possível verificar que a segunda aplicação do Enem 2011 apresentou o maior número de questões (2) sobre a temática biodiesel em uma mesma prova e que a abordagem do biocombustível não é constante no exame, mas tende a aparecer alternadamente e independentemente da sua aplicação. No Novo Enem, por exemplo, a temática só é apresentada na primeira aplicação nos anos de 2014 e 2017.

A presença de itens sobre o biodiesel no exame é conferido pela maior preocupação com as questões ambientais. Outro fator que contribui para isso é a constante busca por alternativas sustentáveis para resolver as crises energéticas no país, que, embora tenham dado um retrocesso, ainda ameaçam retornar. Também pode ser citada a crise econômica que acompanhou o país nos últimos anos, o que colaborou para a venda do pré-sal, afetando a extração do petróleo e, assim, a produção e preço dos combustíveis minerais (Drumond 2017).

\section{Agradecimentos}

Os autores agradecem aos avaliadores anônimos pela revisão crítica do manuscrito.

\section{Referências}

Ambiente Brasil (2004) Viabilidade do óleo vegetal para produção de biodiesel é discutida em Pernambuco. Disponível em: http://noticias.ambientebrasil.com.br/clipping/2004/05/01/14508 -viabilidade-do-oleo-vegetal-para-producao-de-biodiesel-e-discutida-em-pernambuco.html (Acessado em 25/02/2018).

Andrade G.G.A. (2012) Metodologia do Enem: uma reflexão. Série-Estudos, 33: 67-76.

ANP - Agência Nacional do Petróleo, Gás Natural e Biocombustíveis (2016) Biodiesel. Disponível em: http://www.anp.gov.br/wwwanp/biocombustiveis/biodiesel (Acessado em 15/02/2018).

ANP - Agência Nacional do Petróleo, Gás Natural e Biocombustíveis (2017) Consumo de combustíveis no Brasil caiu 4,5\% na comparação entre 2016 e 2015. Disponível em: http:/www.anp.gov.br/wwwanp/noticias/3585-consumo-de-combustiveis-no-brasil-caiu-4-5-nacomparacao-entre-2016-e-2015 (Acessado em 02/01/2017).

Biodieselbr (2017) A validação do B10 pelas montadoras. Disponível em: https://www.biodieselbr .com/noticias/eventos/a-validacao-do-b10-pelas-montadoras.htm (Acessado em 21/02/2018).

Brasil (1997) Lei $\mathrm{n}^{\circ}$ 9.478, de 06 de agosto de 1997. Diário Oficial da União, Poder Executivo, Brasília, DF, 06/08/1997.

Brasil (1998) Portaria $n^{0}$ 438, de 28 de maio de 1998. Diário Oficial da União, Poder Executivo Brasília, DF, 28/05/1998.

Brasil (2002) Portaria MCT no 702, de 30 de outubro e 2002. Diário Oficial da união, Poder Executivo, Brasília, DF, 30/10/2002.

Brasil (2005) Lei $\mathrm{n}^{0}$ 11.097, de 13 de janeiro de 2005. Diário Oficial da União, Poder Executivo, Brasília, DF, 13/01/2005.

Brasil (2016) Lei $\mathrm{n}^{\circ}$ 13.263, de 23 de março de 2016. Diário Oficial da União, Poder Executivo, Brasília, DF, 23/03/2016.

Brasil (2017) Necessidade de atendimento especial deve ser comprovada. Disponível em: http://portal.mec.gov.br/busca-geral/212-noticias/educacao-superior-1690610854/48371-neces sidade-de-atendimento-especial-deve-ser-comprovada (Acessado em 19/02/2018).

Cruz G. (2011) ENEM e os novos rumos do vestibular. Educatrix, 1: 84-87.

Drummond C. (2017) A venda do pré-sal, um desastre para o Brasil. Disponível em: https://www.c artacapital.com.br/revista/977/a-venda-do-pre-sal-um-desastre-para-o-brasil (Acessado em 25/ 02/2018). 
Enem - Exame Nacional do Ensino Médio (2017) Para pessoas privadas de liberdade será aplica do nos dias 12 e 13 de dezembro. Disponível em: https:/g1.globo.com/educacao/enem/2017/n oticia/enem-2017-para-pessoas-privadas-de-liberdade-sera-aplicado-nos-dias-12-e-13-de-dezem bro.ghtml (Acessado em 15/02/2018).

Ferreira E.M. (2014) Análise da abrangência da matriz de referência do ENEM com relação às habilidades avaliadas nos itens de Matemática de 2009 a 2013. Dissertação de Mestrado, Programa de Mestrado Profissional em Matemática em Rede Nacional. Universidade de Brasília, DF, Brasília.

Garcia C.M. (2006) Transesterificação de óleos vegetais. Dissertação de Mestrado, Programa de Pós-Graduação em Química Inorgânica. Universidade de Brasília, DF, Brasília.

Geris R., Santos N.A.C., Amaral B.A., Maia I.S., Castro V.D. \& Carvalho J.R.M. (2007) Biodiesel de soja: reação de transesterificação para aulas práticas de Química Orgânica. Química Nova, 30(5): 1369-1373. DOI: 10.1590/S0100-40422007000500053

INEP - Instituto Nacional de Estudos e Pesquisas Educacionais (1998) Enem: documento básico. Disponível em: http://portal.inep.gov.br/documents/186968/484421/Exame+Nacional+do+Ens ino+M\%C3\%A9dio+-+ENEM++documento+b\%C3\%A1sico/e2cf61a8-fd80-45b8-a36f-af6940e56 113?version=1.1 (Acessado em 24/02/2018).

INEP - Instituto Nacional de Estudos e Pesquisas Educacionais (2017) Provas e gabaritos Enem. Disponível em: http://inep.gov.br/provas-e-gabaritos (Acessado em 15/01/2018).

Knothe G., Gerpen J.V., Krahl J. \& Ramos L.P. (2006) Manual do Biodiesel. São Paulo: Edgard Blucher. $352 \mathrm{p}$.

Maceno N.G., Ritter-Pereira J., Maldaner O.A. \& Guimarães O.M. (2011) A Matriz de Referência do ENEM 2009 e o Desafio de Recriar o Currículo de Química na Educação Básica. Química Nova na Escola, 33(3): 153-159.

Marcelino L.V. \& Recena M.C.P. (2012) Possíveis influências do novo ENEM nos currículos educacionais de química. Estudos em Avaliação Educacional, 23(53): 148-177.

Mattei L. (2010) Programa Nacional para Produção e Uso do Biodiesel no Brasil (PNPB): trajetória, situação atual e desafios. Revista Econômica do Nordeste, 41(4): 731-740.

Mendonça M.A.A., Freitas R.E., Santos A.O.P., Pereira A.S. \& Costa R.C. (2008) Expansão da produção de álcool combustível no Brasil: uma análise baseada nas curvas de aprendizagem (p. 01-15). In: XLVI Congresso da Sociedade Brasileira de Economia, Administração e Sociologia Rural. Rio Branco: Sociedade Brasileira de Economia, Administração e Sociologia Rural.

Mota C.J.A., Silva C.X.A. \& Goncalves V.L.C. (2009) Gliceroquímica: novos produtos e processos a partir da glicerina de produção de biodiesel. Química Nova, 32(3): 639-648. DOI: $10.1590 /$ S0100-40422009000300008

Parra L. (2003) Óleo de girassol é usado como combustível. Disponível em: https://www.folhadelondrina.com.br/economia/oleo-de-girassol-e-usado-como-combustivel-44 6281.html (Acesso em 21/02/2018).

Rinaldi R., Garcia C., Marciniuk L.L., Rossi A.V. \& Schuchardt U. (2007) Síntese de biodiesel: uma proposta contextualizada de experimento para laboratório de química geral. Química Nova, 30(5): 1374-1380. DOI: 10.1590/S0100-40422007000500054

Santos A.P.B. \& Pinto A.C. (2009) Biodiesel: uma alternativa de combustível limpo. Química Nova na Escola, 31(1): 58-62.

Suarez P.A.Z. \& Meneghetti S.M.P. (2007) $70^{\circ}$ aniversário do biodiesel em 2007: evolução histórica e situação atual no Brasil. Química Nova, 30: 2068-2071. DOI: 10.1590/S010040422007000800046

Suarez P.A.Z., Meneghetti S.M.P., Meneghetti M.R. \& Wolf C.R. (2007) Transformação de triglicerídeos em combustíveis, materiais poliméricos e insumos químicos: algumas aplicações da catálise na oleoquímica. Química Nova, 30: 667-676. DOI: 10.1590/S010040422007000300028 
Temática biodiesel no Enem

Vasconcelos Y. (2016) No ranking de desenvolvimento tecnológico. Disponível em: https://super.abril.com.br/ciencia/no-ranking-de-desenvolvimento-tecnologico/ (Acesso em: 19/12/2017). 